\title{
PENGEMASAN MATERI PEMBELAJARAN TARI MUNALO BERBASIS BLENDED LEARNING UNTUK SISWA SMA NEGERI 8 TAKENGON
}

\author{
Selvi Yuliantika', Inggit Prastiawan². \\ Program Studi Pendidikan Tari, Fakultas Bahasa dan Seni,Universitas Negeri Medan \\ Jalan Willem Iskandar Pasar V Medan Estate 20221, Sumatera Utara-Indonesia \\ Email: ${ }^{1}$ selviyuliantika9@ gmail.com, ${ }^{2}$ inggitprastiawan@ yahoo.com
}

\begin{abstract}
This study aims to describe the steps for packing the Munalo Dance learning material based on blended learning for students of SMAN 8 Takengon. The theory made in this study uses a theory from Dwiyogo (2018: 59) which reveals that blended learning refers to learning that combines or mixes between face to face learning and computer-based learning (online and offline). In this research process the method used in this study is a qualitative method. The population is cultural arts teacher and $\mathrm{X}$ grade students of SMAN 8 Takengon while the research sample is cultural arts teacher and 12 students of SMAN 8 Takengon. The technique of collecting data is done by observation, interviews, literature studies, and documentation. These data are then analyzed by qualitative descriptive methods. This packaging is in KD.3.1 syllabus for dance class X. For this reason, it takes 3 stages, namely the analysis phase, the evaluation stage and stage. The learning material for Munalo Dance based on blended learning has been tested by media experts and material experts so that it is very feasible to be used as learning media. The research results obtained were Munalo Dance learning materials packed in VCD form, which can be learned through the website http://www.sman8 takengonunggul.sch.id (based online) and used as a learning medium when face-to-face offline)
\end{abstract}

Keywords: Packaging Learning Materials, Munalo Dance, Blended Learning

\begin{abstract}
ABSTRAK
Penelitian ini bertujuan untuk mendiskripsikan langkah-langkah pengemasan materi pembelajaran Tari Munalo berbasis blended learning untuk siswa SMAN 8 Takengon. Teori yang di jadikan dalam penelitian ini menggunakan teori dari Dwiyogo (2018:59) yang mengungkapkan bahwa blended learning mengacu pada belajar yang mengombinasikan atau mencampur antara pembelajaran tatap muka (face to face) dan pembelajaran berbasis komputer (online dan offline). Pada proses penelitian ini metode yang di gunakan pada penelitian ini adalah metode kualitatif. Populasinya guru seni budaya dan siswa-siswi kelas X SMAN 8 Takengon sedangkan Sampel penelitiannya guru seni budaya dan 12 siswa-siswi SMAN 8 Takengon. Teknik pengumpulan data di lakukan dengan cara observasi, wawancara, studi kepustakaan, dan dokumentasi. Data-data ini kemudian di analisis dengan metode deskriptif kualitatif. Kemasan ini di susun berdasarkan KD.3.1 silabus seni tari kelas X. Untuk itu, dibutuhkan 3 tahapan yaitu tahap analisis, tahap rancangan dan tahap evaluasi. Materi pembelajaran berbasis blended learning ini telah diuji kelayakan oleh ahli media dan ahli materi sehingga sangat layak untuk dijadikan media pembelajaran. Hasil penelitian yang di peroleh adalah materi pembelajaran Tari Munalo di kemas dalam bentuk VCD, yang dapat di pelajari melalui website http://www.sman8takengonunggul.sch.id (berbasis online) dan di gunakan sebagai media pembelajaran saat tatap muka (offline).
\end{abstract}

Kata kunci : Pengemasan Materi Pembelajaran, Tari Munalo, Blended Learning 


\section{PENDAHULUAN}

Sekolah merupakan tempat belajar formal bagi siswa untuk mendapatkan pendidikan, agar siswa menjadi manusia yang berguna demi kemajuan bangsa. Sekolah merupakan lembaga pendidikan yang penting untuk siswa dalam proses belajar mengajar yang mempunyai peran penting dalam keberhasilan siswa menerima dan menguasai pelajaran. Guru sebagai tenaga pendidik merupakan hal yang penting dalam berlangsungnya suatu proses belajar mengajar, yang dapat mentransferkan ilmu pengetahuan dan menerapkan berbagai pendekatan pembelajaran, strategi pembelajaran, metode pembelajaran dan model pembelajaran pada siswa.

Dalam berlangsungnya suatu proses pembelajaran tentunya harus didukung dengan adanya silabus dan RPP dalam suatu pembelajaran, agar mempermudah dan memperlancar pemberian suatu materi pembelajaran kepada siswa. Misalnya dalam penyampaian materi pembelajaran, pastinya memiliki beragam metode yang akan di sampaikan kepada siswa. Salah satunya metode demonstrasi. Metode ini sering dilakukan di sekolah-sekolah yang ada di Kota Takengon terutama pada pembelajaran tari.

Berdasarkan dari observasi yang dilakukan penulis, SMAN 8 Takengon adalah salah satu sekolah negeri yang terdapat di daerah Takengon, merupakan sekolah yang pada saat sekarang ini terus berbenah diri untuk menjadi sekolah yang berkembang dalam bidang pendidikan, baik dari jenis literatur sebagai bahan bacaan maupun dari segi pembangunan ruang serta sarana prasarana belajar lainnya, sesuai dengan perkembangan zaman dan teknologi. Untuk menentukan keberhasilan pelaksanaan pendidikan di sekolah, juga ditentukan oleh kualitas pembelajaran dan makna belajar mengajar, sebagai suatu proses pengajaran untuk mencapai tujuan pembelajaran yang efektif dan optimal.

Pembelajaran seni budaya di SMAN 8 Takengon sangat mendukung siswanya untuk mengetahui budaya yang ada di daerahnya sendiri, salah satunya yaitu dalam bidang tari. Jika dilihat pada silabus seni tari kelas $\mathrm{X}$ semester 1, kompetensi dasar (KD 3.1) yang dipelajari adalah memahami konsep, teknik, dan prosedur dalam menirukan ragam gerak tari tradisi daerah setempat, dalam hal ini Tari Munalo. Dengan demikian, kompetensi yang di harapkan untuk apresiasi dapat tersampaikan, materi yang disampaikan yaitu meliputi konsep Tari Munalo, teknik Tari Munalo dan prosedur dalam menirukan ragam gerak Tari Munalo.

Dari observasi yang penulis lakukan di SMAN 8 Takengon di peroleh data bahwa Tari Munalo yang dibelajarkan tidak berjalan efektif dan efisien. Hal ini disebabkan karena sarana dan prasarana yang dimiliki oleh sekolah tidak dimanfaatkan dengan baik, seperti media komputer, dan ketersediaan jaringan internet, sarana ini hanya dipakai saat melaksanakan UNBK.

Menurut penulis, kenyataan ini menjadi salah satu penyebab kurang optimalnya penguasaan kompetensi siswa terhadap materi 
pembelajaran seni budaya, terutama materi Tari Munalo dan juga belum di lakukannya materi pembelajaran dengan model blended learning, baik sekolah-sekolah yang ada di daerah Takengon maupun di SMAN 8 Takengon. Berdasarkan kenyataan itu penulis berdiskusi dengan guru mata pelajaran seni budaya untuk menyediakan media pembelajaran yaitu blended learning, dalam diskusi penulis menjelaskan bahwa dalam blended learning ini guru dan siswa sama-sama dimudahkan dalam suatu proses belajar mengajar. Tetapi setelah di amati, dengan adanya media dalam pembelajaran tentunya masih ada kekurangan dalam penyampaian materi yaitu model pembelajaran yang dapat mendorong terciptanya proses belajar mengajar.

Demi menciptakan pembelajaran yang berporos pada siswa, guru sangat mengharapkan siswa mampu mengembangkan bakatnya, memperluas wawasan atau pengetahuan dan mempermudah siswa dalam mengingat sebuah pembelajaran tari yaitu dengan mengemas materi pembelajaran berbasis internet yang didalamnya ada sistem pembelajaran berbasis web. Agar siswa cepat dalam memahami materi yang diberikan guru, materi yang akan dikemas adalah dengan media audio visual yang isinya merupakan satu bentuk tarian yang utuh, ada gambar dan ada penjelasan pembagian secara kontektual dari materi yang akan diberikan.

Hal ini berkaitan dengan semakin tingginya kebutuhan informasi ilmu pengetahuan dan teknologi yang tidak semuanya diperoleh dalam lingkungan sekolah.
Oleh karena itu, perlu dikembangkan suatu model pembelajaran yang dapat mengembangkan kompentensi guru sesuai dengan tuntutan zaman yaitu dengan model blended learning.

Blended learning adalah sebuah kemudahan pembelajaran yang menggabungkan berbagai cara penyampaian, model pengajaran, gaya pembelajaran dan memperkenalkan berbagai pilihan media dialog antara fasilitator dengan orang yang mendapat pengajaran, serta blended learning sebagai sebuah kombinasi pengajaran langsung (face to face) dan pengajaran online, tapi lebih dari pada itu sebagai elemen dari interaksi sosial, Dwiyogo (2014:16). Hal ini memberikan gambaran bahwa blended learning merupakan kombinasi antara pembelajaran tatap muka dan pembelajaran online dengan bantuan teknologi informasi dan komunikasi secara tepat guna untuk mencapai tujuan pembelajaran.

Berdasarkan persoalan-persoalan tersebut penulis tertarik untuk mencoba memberikan suatu solusi dengan mengemas materi dengan model blended learning. Untuk dapat memudahkan dalam memahami isi materi, penulis ingin melakukan penelitian dengan judul "Pengemasan Materi Pembelajaran Tari Munalo Berbasis Blended learning Untuk Siswa SMA Negeri 8 Takengon".

Teori yang dipakai dalam penelitian ini adalah teori dari Dwiyogo (2018:59) mengungkapkan "blended learning mengacu pada belajar yang mengombinasi atau mencampur antara pembelajaran tatap muka 
(face to face $=\mathrm{f} 2 \mathrm{f}$ ) dan pembelajaran berbasis komputer (online dan offline)".

Penelitian ini dilakukan di SMAN 8 Takengon dimana lokasi penelitian ini tepatnya terletak di Jalan Kebet Kecamatan Bebesen Kabupaten Aceh Tengah. Waktu penelitian dan proses penelitian ini dilakukan pada Agustus sampai dengan Oktober 2018. Populasi dalam penelitian ini adalah guru seni budaya dan siswa-siswi SMAN 8 Takengon. Sampel penelitian ini adalah guru seni budaya dan 12 siswa-siswi SMAN 8 Takengon. Teknik Pengumpulan Data yang dilakukan adalah sebagai berikut: 1. Observas, 2. Dokumentasi, 3. wawancara, 4. Studi Kepustakaan.

Dalam penelitian ini dibutuhkan tahap kelayakan produk yang dapat mengukur sejauh mana keberhasilan produk yang dihasilkan dalam hal ini menggunakan validasi ahli. Validasi ahli media dan ahli materi dilakukan untuk menilai kelayakan produk dari segi penyajian media dan materi untuk diuji cobakan dilapangan. Penilaian, kritik dan saran dari validator akan digunakan sebagai bahan perbaikan dan penyempurnaan media pembelajaran berbasis Blended learning. Penilaian dilakukan melalui angket uji kelayakan ahli media dan ahli materi

Instrumen penelitian media pembelajaran berbasis blended learning ini digunakan dengan angket untuk mengevaluasi media pembelajaran yang akan dikemas. Angket ini disusun oleh penulis dikategorikan layak digunakan apabila mendapat skor ratarata minimal baik untuk masing-masing komponen.
Data yang digunakan dalam penelitian ini adalah data kualitatif dan data kuantitatif. Data kualitatif diperoleh berdasarkan dari hasil observasi, wawancara, dokumentasi dan studi kepustakaan. Sedangkan data kuantitatif di dapat dari kisi-kisi instrumen penilaian dari ahli media dan ahli materi. Kedua data ini dideskripsika secara kualitatif. Maka teknik analisis data yang digunakan dalam penelitian ini adalah deskriptif kualitatif.

\section{HASIL DAN PEMBAHASAN}

\section{Rancangan Pembelajaran Blended Learning}

1. Tahap Analisis

a. Analisis Kebutuhan Pemecahan Masalah

Pembelajaran yang menekankan bagaimana membelajarkan tari muatan lokal, maka Tari Munalo dipilih sebagai materi untuk menjawab KD 3.1 pada silabus seni tari kelas X. Sampai saat ini pembelajaran Tari Munalo masih menggunakan metode konvensional yaitu masih berpusat pada guru (teacher center learning), untuk mengubah sistem pembelajaran yang konvensional ini menjadi sistem pembelajaran yang terkini berbasis digital, maka disusunlah pembelajaran Tari Munalo berbasis blended learning dengan menggunakan website sekolah dan pembelajaran tatap muka dengan materi yang sama.

b. Identifikasi Sumber Belajar dan Kendala

Sampai sejauh ini sumber belajar yang dimiliki sekolah hanya sebatas berbentuk buku yang berisi tentang berbagai tarian daerah Gayo dan buku ini masih sebatas dimiliki oleh guru yang menjadi pegangan yang bersifat tidak 
pasif. Artinya guru juga tidak mempunyai pegangan buku secara optimal untuk menyampaikan materi-materi tentang tarian daerah setempat. Oleh karena itu, pengemasan Tari Munalo sebagai bagian dari sumber belajar siswa untuk menguasai seni tari daerah setempat dianggap perlu dilakukaan dengan mengemasnya dalam bentuk VCD yaitu berbasis online dan berbasis offline. Jika materi yang dikemas berbasis online yaitu dapat di pelajari melalui website SMAN 8 Takengon sedangkan berbasis offline dapat dipelajari dalam bentuk VCD dengan materi yang sama.

c. Identifikasi Karakteristik Pebelajar

Identifikasi pebelajar di SMAN 8 Takengon baik secara keseluruhan siswa kelas $\mathrm{X}$ maupun 12 Siswa-siswi yang dijadikan sampel adalah berasal dari etnis Gayo. Sesuai dengan tuntutan KD 3.1 semua siswa harus menguasai tari daerah setempat dengan optimal dalam hal ini dipilihlah Tari Munalo sebagai materi pembelajaran.

\section{Tahap Rancangan}

a. Menetapkan Tujuan Pembelajaran

Tujuan pembelajaran yaitu:

1. Siswa mampu menganalisis konsep Tari Munalo.

2. Siswa mampu merincikan bagianbagian dari ragam gerak Tari Munalo.

3. Siswa mampu menghubungkan prosedur belajar Tari Munalo offline dan online.

b. Memilih dan Menetapkan Strategi Pembelajaran.

Strategi pembelajaran yang digunakan oleh guru adalah strategi expository, yaitu strategi pembelajaran yang menekankan kepada proses penyampaian materi secara verbal dari seorang guru kepada siswa agar maksud siswa dapat menguasai materi pelajaran secara optimal.

c. Mengembangkan Sumber Belajar (tatap muka, offline dan online) Sumber belajar dalam hal ini yaitu:

1. Tatap muka

Pembelajaran tatap muka adalah kegiatan pembelajaran yang berupa interaksi langsung antara peserta didik dan pendidik.

\section{Offline}

Pembelajaran berbasis offline dapat di laksanakan melalui pembelajaran berbasis komputer, medianya yang bersifat offline dapat diwujudkan dalam bentuk CD atau DVD.

\section{Online}

Pengajaran dan pembelajaran online yang menggunakan rangkaian elektronik (LAN, WAN, atau internet) untuk menyampaikan isi pembelajaran, interaksi, atau bimbingan. Dengan cara ini jumlah pembelajar yang bisa ikut berpatisipasi bisa jauh lebih besar dari pada cara belajar konvensional di ruang kelas.

3. Tahap Evaluasi

a. Uji Coba

Pengemasan materi pembelajaran Tari Munalo dalam bentuk VCD sudah diujicobakan di lingkungan sekolah tersebut dalam website http://www.sman8Takengonunggul.sch.id yang dimiliki SMAN 8 Takengon.

b. Revisi

Revisi ini di lakukan oleh penulis bersama validator Ahli Media yaitu bapak Raden Burhan SND, S.Pd., M. Ds dan validator Ahli Materi yaitu Ibu Rika Restela, M.Pd 
menyangkut materi Tari Munalo yang di kemas dalam bentuk VCD.

c. Prototipe Rancangan Pembelajaran Berbasis Blended Learning.

Dalam hal ini prototipe rancangan pembelajaran berbasis blended learning di kemas dalam bentuk VCD untuk di gunakan sebagai media pembelajaran tatap muka, offline dan online.

\section{Langkah-Langkah}

Pengemasan

Pembelajaran Tari Munalo Berbasis

\section{Blended learning.}

Materi pembelajaran Tari Munalo yang dikemas dalam bentuk video yang menarik, dengan alam lingkungan Kota Takengon, Danau Lut Tawar, masyarakat Gayo serta penggunungan daerah Kota Takengon. Melalui video pembelajaran ini, siswa dapat menganalisis sejarah dan sinopsis Tari Munalo, siswa dapat merincikan bagian-bagian ragam gerak Tari Munalo yang benar dan siswa dapat menghubungkan prosedur belajar Tari Munalo. Penyiapan suatu materi harus sejalan dengan tujuan pembelajaran yang tertera dalam silabus pembelajaran Kurikulum 2013. Adapun materi yang dikemas pada kompetensi dasar (3.1) yaitu memahami konsep, teknik dan prosedur dalam menirukan ragam gerak tari tradisi daerah setempat, dalam hal ini yaitu:

\section{Konsep Tari Munalo}

Konsep dari Tari yang dibuat di dalam video berisi tulisan tentang judul media pembelajaran Tari Munalo, asal mula Tari Munalo, dan sinopsis dari Tari Munalo.
2. Ragam Gerak dan Teknik Melakukan Ragam Gerak Tari Munalo

Adapun teknik gerak Tari Munalo berisikan slide foto per-ragam gerak disertai nama tiap ragam gerak. Gerakan dalam tarian ini yakni gerakan ras (lari) motif geraknya adalah gerdak dah papan (gertak papan), semar kalang (burung elang mencakar), kepur nunguk (kipas sayap burung pungguk), jangin (memohon ijin), sining lintah (lintah berenang), munatap penari Guel (laki-laki), salam semah (salam sembah), kipes, puter tali, munatap penari guel dan munatap penari Munalo (laki-laki dan perempuan), redep/Dep (berdiri), cicang nangka (bergembira), runcang (bebas), transisi (gerak penghubung), ketibung (menggiring gajah).

3. Prosedur Pembelajaran Tari Munalo.

Prosedur yang dimaksud adalah serangkaian tahapan secara spesifik yang harus dijalankan dengan cara yang sama untuk memperoleh hasil yang sama seperti dalam pelaksanaan Tari Munalo, dalam hal ini prosedur Tari Munalo dibagi menjadi dua bagian yaitu, prosedur belajar Tari Munalo dan Bentuk Evaluasi.

\section{PENUTUP}

\section{A. Kesimpulan}

Berdasarkan pada hasil penelitian dan pembahasan, maka penelitian ini mengambil kesimpulan sebagai berikut

1. Rancangan pembelajaran blended learning di butuhkan 3 tahapan yaitu tahap analisis, tahap rancangan dan tahap evaluasi. Dari uji kelayakan ahli media 
diperoleh skor 4,77, sedangkan uji kelayakan ahli materi diperoleh skor 4,25 artinya bahwa materi pembelajaran berbasis blended learning sangat layak untuk dijadikan media pembelajaran.

2. Langkah-langkah pengemasan materi pembelajaran Tari Munalo ini harus sejalan dengan tujuan pembelajaran yang tertera dalam silabus pembelajaran Kurikulum 2013. Adapun materi yang di kemas pada kompetensi dasar (3.1) yaitu memahami konsep, teknik dan prosedur dalam menirukan ragam gerak tari tradisi daerah setempat.

3. Pengemasan materi pembelajaran Tari Munalo berbasis blended learning berisi materi Tari Munalo yang didalamnya video pembelajaran tentang 1). konsep Tari Munalo yang terdiri dari judul Tari Munalo, asal mula tari Munalo, sinopsis Tari Munalo. 2. ragam gerak dan teknik melakukan gerak Tari Munalo yang berisi tentang slide per-ragam dari tarian Munalo serta cara melakukan gerak Tari Munalo dan 3. prosedur pembelajaran Tari Munalo yang terdiri dari prosedur belajar dan bentuk evaluasi.

4. Hasil penelitian yang diperoleh adalah materi pembelajaran Tari Munalo di kemas dalam bentuk VCD, yang dapat di pelajari melalui http://www.smans takengonunggul.sch.id (berbasis online) dan digunakan sebagai media pembelajaran saat tatap muka (offline).

\section{B. Saran}

Berdasarkan kesimpulan di atas, penulis memberikan saran-saran sebagai berikut:

1. Untuk SMAN 8 Takengon agar memanfaatkan materi pembelajaran Tari Munalo yang sudah di kemas ini dengan sebaik-baiknya agar bisa di akses oleh siswa, sehingga tuntutan berbasis digital zaman sekarang ini bisa terjawab oleh SMAN 8 Takengon

2. Pengemasan materi berbasis blended learning boleh dilakukan dengan kompetensi dasar selain materi tari dengan media-media yang lainnya. Sehingga pembelajaran dapat bervariasi.

\section{DAFTAR PUSTAKA}

Arnita. 2016. Pengantar Statistika. Bandung: Cita Pustaka.

Arsyad, Azhar. 2014. Media Pembelajaran. Jakarta: Raja grafindo Persada.

Arikunto, Surhasimi. 2014. Prosedur Penelitian suatu Pendekatan Praktik. Jakarta: PT. Rineka Cipta.

Cut Dalila, 2017. Pengemasan Tari Manoe Pucok Berbasis Audio Visual Bagi Siswa Sekolah Menengah Pertama. Skripsi Universitas Negeri Medan.

Daryanto, 2018. Media Pembelajaran. Bandung: Satu Nusa.

Desma armida, 2016. Pengaruh Model Pembelajaran Blended Learning Terhadap Kemampuan Gitar Pop Siswa Kelas VIII SMP Negeri 12 Medan. Skripsi Universitas Negeri Medan. 
Dwiyogo, Wasis, 2018. Pembelajaran Berbasis Blended Learning. Depok: PT. Raja Grafindo Persada.

Hamalik, Oemar. 2014. Media Pembelajaran. Yogyakarta: Balai Pustaka.

Husamah, 2014. Pembelajaran Bauran (Blended Learning). Jakarta: Prestasi Pustakaraya.

Husni Idris, 2011. "Pembelajaran Model Blended Leaning". E-Journal Pendidikan.

Keller, kotler, 2013. Manajemen Pemasaran. Jakarta: Erlangga.

Meleong, 2017. Metodologi Penelitian Kualitatif. Bandung:PT. Remaja Rosdakarya Bandung.

Milawati, 2011, Kontinuitas Dan Perubahan Tari Munalo Pada Upacara Adat Perkawinan Masyarakat Gayo Kabupaten Aceh Tengah (Takengon). Skripsi Universitas Negeri Medan.

Prihadi, Singgih, 2013. Model Blended Learning Teori dan Praktek Dalam Pembelajaran Geografi. Surakarta: Yuma Pustaka.

Rita Kurniati, 2014. Pengembangan Model Pembelajaran Blended Learning Pada Mata Pelajaran Keterampilan Komputer dan Pengelolaan Informasi (KKPI) Kelas XI Di SMK Negeri 2 Purwodadi. Skripsi Universitas Negeri Semarang.

Riska Prisilla, 2014. Deskripsi Pertunjukan Tari Munalo dan Musik Iringan Pada Upacara Perkawinan Adat Gayo di Medan Sunggal. Skripsi Universitas Sumatera Utara.

Sanjaya, Wina. 2017. Strategi Pembelajaran Beorientasi Standar Proses Pendidikan. Jakarta: Kencana.
Sarah Bibi dan Handaru Jati, 2015. "Efektivitas Model Blended Learning Terhadap Motivasi dan Tingkat Pemahaman mahasiswa Mata Kuliah Algoritma dan Pemrograman. E-Journal Pendidikan.

Sugiyono, 2016. Metode Penelitian Kuantitatif, Kualitatif, dan $R \& D$. Bandung: Alfabeta.

Susilana, Rudi dan Cepi Riyana, 2017. Media Pembelajaran. Bandung: CV. Wacana Prima.

Suciati Simahbengi, 2017. Pengemasan Tari Guel Dalam Bentuk Kartu Pos Sebagai Media Pembelajaran. Skripsi Universitas Negeri Medan.

Sastrinda Azzarista, 2012. Musik Pengiring Tari Munalo Dalam Upacara Adat Perkawinan Di Kecamatan Bukit Simpang Tiga Kabupaten Bener Meriah. Skripsi Universitas Negeri Medan.

Sulihin B.Sjukur, 2012. "Pengaruh Blended Learning Terhadap Motivasi Belajar dan Hasil Belajar Siswa Tingkat SMK'. E-Journal Pendidikan. 